\title{
AN AXIAL ROTATION GONIOMETER: BRIEF REPORT
}

\author{
WIROON LAUPATTARAKASEM
}

Certain joint movements, especially axial rotations, are more difficult to measure than others; forearm supination and pronation are examples (AAOS 1966). With a standard plastic goniometer measurement is only approximate, though if the patient holds a stick while pronating and supinating (McRae 1976) measurement is easier. The action of gripping, and movements of the wrist and fingers can, however, produce errors. A new gravity-activated goniometer with wrist stabilisation cuffs has therefore been designed (Fig. 1).

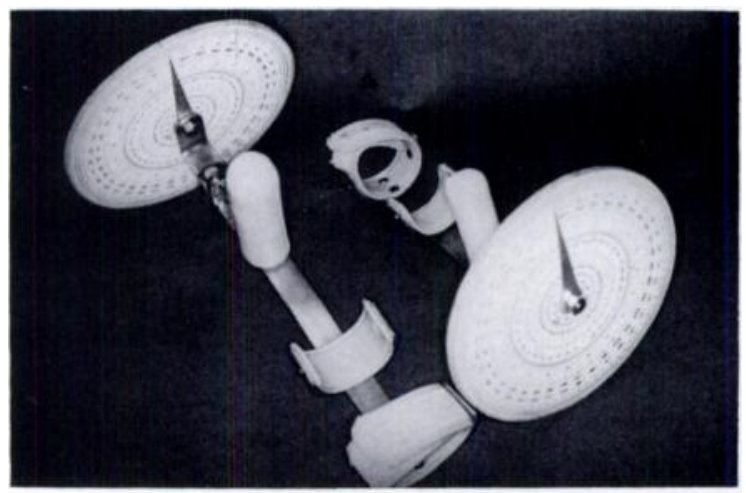

Fig. 1

Method. The humerus must be kept vertical throughout the measurement. This is accomplished by asking the patient to keep the arm firmly adducted to the body and to lean laterally against a wall. The goniometer is applied and strapped to the forearm. The elbow is then flexed $90^{\circ}$ and the forearm rotated to the neutral position (Fig. 2) with the indicator pointing to zero and vertical. The amplitude of supination and pronation can then be measured accurately on the dial, which is marked in degrees.

Results. In order to test the reliability of the goniometer, 100 upper limbs of 50 adult volunteers were tested. The amount of pronation and supination in each was measured by two residents independently and their findings statistically tested for inter-observer reliability using the Pearson product-moment correlation. The correlation coefficients were 0.96 and $0.95(p<0.001)$

W. Laupattarakasem, MD, FICS, FRCST, Associate Professor of Orthopaedic Surgery

Faculty of Medicine, Khon Kaen University, Khon Kaen 40002 Thailand.

(C) 1989 British Editorial Society of Bone and Joint Surgery $0301-620 X / 89 / 1$ R $90 \$ 2.00$

J Bone Joint Surg [Br] 1989:71-B:137.

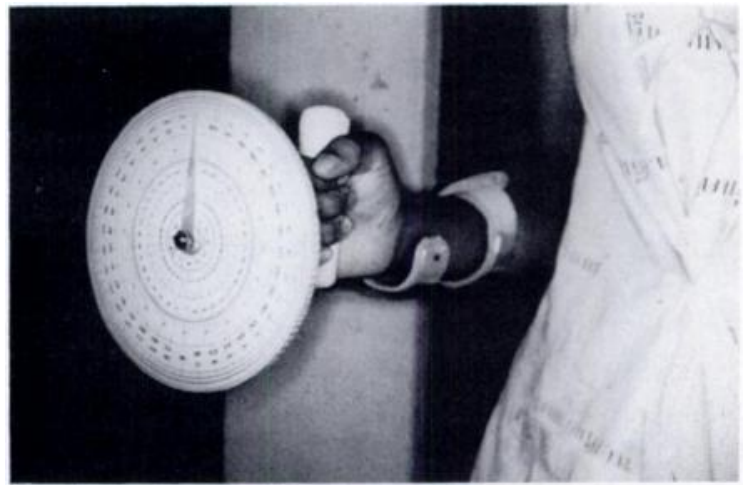

Fig. 2

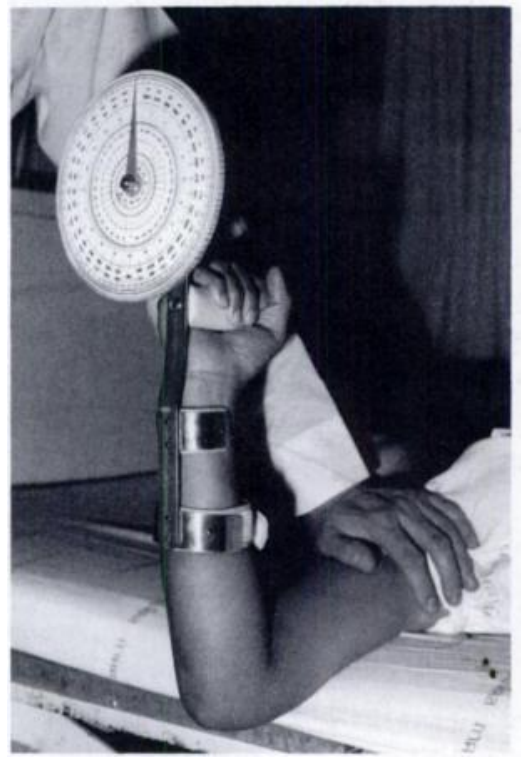

Fig. 3

for supination and pronation of the right side and 0.97 and $0.90(p<0.001)$ respectively for the left side.

Discussion. These statistical findings demonstrate a high inter-observer reliability in measuring forearm supination and pronation. The goniometer can also be used to measure rotation of the abducted shoulder (Fig. 3).

No benefits in any form have been received or will be received from a commercial party related directly or indirectly to the subject of this article.

\section{REFERENCES}

American Academy of Orthopaedic Surgeons. Joint motion: method of measuring and recording. AAOS, 1965 Edinburgh, etc: E \& S Livingstone, reprinted 1966.

McRae, R. Clinical orthopaedic examination. Edinburgh, etc: Churchill Livingstone, 1976. 